\title{
Effect of cranberry juice concentrate on chemically-induced urinary bladder cancers
}

\author{
JEEVAN K. PRASAIN ${ }^{1}$, KENNETH JONES $^{1}$, RAY MOORE $^{4}$, STEPHEN BARNES ${ }^{1,4}$, MARGE LEAHY ${ }^{5}$, \\ ROBIN RODERICK ${ }^{5}$, M. MARGARET JULIANA ${ }^{2}$ and CLINTON J. GRUBBS ${ }^{3}$

\begin{abstract}
Departments of ${ }^{1}$ Pharmacology and Toxicology, ${ }^{2}$ Genetics and ${ }^{3}$ Surgery and ${ }^{4}$ Comprehensive Cancer Center Mass Spectrometry Shared Facility and Purdue-UAB Botanicals Center for Age-Related Diseases, University of Alabama, Birmingham, AL; ${ }^{5}$ Ocean Spray Cranberries, Inc., Lakeville, MA, USA
\end{abstract}

Received December 20, 2007; Accepted February 7, 2008

\begin{abstract}
The chemopreventive efficacy of cranberry juice concentrate in an experimental model of urinary bladder cancer was evaluated using female Fischer-344 rats. The animals received N-butyl-N-(4-hydroxybutyl)-nitrosamine $(\mathrm{OH}-\mathrm{BBN})$ for a period of eight weeks. Cranberry juice concentrate was administered at doses of 1.0 or $0.5 \mathrm{ml} / \mathrm{rat} /$ day beginning one week after the final OH-BBN treatment and continuing until the end of the study. The urinary bladders of all the rats were weighed and examined grossly for lesions, and all masses were submitted for pathological evaluation. A dose-dependent preventive effect of cranberry treatment was observed, with a reduced number of urinary bladder cancers $(38 \%)$ in the $1.0 \mathrm{ml} / \mathrm{rat} /$ day group versus the control group. The cranberry extract neither affected body weight gain nor caused other signs of toxicity. For the metabolic studies, serum and urine were collected at 4 and $12 \mathrm{~h}$ after the administration of the cranberry juice concentrate and were analyzed by LCMS/MS. Quercetin and its methylated derivative were detected in the urine samples. However, no quercetin was detected in the serum samples, indicating its poor bioavailability. These data suggest that components of cranberries may be effective in preventing urinary bladder carcinogenesis.
\end{abstract}

\section{Introduction}

Numerous epidemiological data have supported the inverse relationship between the consumption of fruit and vegetables and the incidence of urinary bladder cancer $(1,2)$. The

Correspondence to: Dr Clinton J. Grubbs, Department of Surgery, Volker Hall, Room G78D, 1530 3rd Avenue South, Birmingham, AL 35294-0019, USA

E-mail: clinton.grubbs@ccc.uab.edu

Abbreviations: OH-BBN, 4-hydroxybutyl(butyl)nitrosamine; UTI, urinary tract infections; MRM, multiple reaction monitoring

Key words: cranberry juice, urinary bladder, cancer, chemical carcinogen preventive effects of green tea leaves and one of its major components, epigallocatechin gallate (EGCG), have been reported for bladder cancer $(3,4)$. The role of diet as a cause of urinary bladder carcinogenesis is feasible since most substances and/or their metabolites (including carcinogens) are excreted through the urinary tract. Importantly, the urinary concentration of these substances is substantially higher than in other tissues, thereby, enhancing their harmful activity. Foods that also contain significant amounts of cancer-preventive components may provide desirable health benefits beyond a basic nutritional function.

The American cranberry (Vaccinium macrocarpon) contains the highest percentage of polyphenols by weight among 20 fruits analyzed in a previous study (5). Cranberry juice is well known for its possible beneficial effects in urinary tract infections (UTI), and considerable attention has been given to its active components and mechanism of action in vivo (6). Quercetin (Fig. 1), one of the major phytochemicals of the cranberry, has been reported to be a growth inhibitor of primary bladder transitional cell cancers in humans (7). Cancers of the urinary bladder were not observed in rats given a $5 \%$ quercetin diet (8). Synergistic or additive antiproliferative interactions of phytochemicals in a cranberry extract have recently been reported in several human tumor cell lines (9).

Cranberry juice may be active in the prevention of UTI by blocking cell proliferation. Non-steroidal anti-inflammatory drugs (NSAIDs), which have antiproliferative activity, have been shown in our laboratories to be highly active in preventing urinary bladder cancer (10). It was felt, therefore, that cranberry juice may be active in preventing urinary bladder carcinogenesis due to its antiproliferative activity. Preliminary data on the preventive activity of cranberries in vitro exist (11). However, there have been no reports on their preventive efficacy against urinary bladder cancer in vivo. In our study, the effect of cranberry juice concentrate on urinary bladder carcinogenesis induced by a chemical carcinogen was investigated, and the metabolic fate of its major flavonoid (quercetin) in urine and blood was determined by LC-MS/MS.

\section{Materials and methods}

Chemicals and animals. Female Fischer-344 rats were obtained from Harlan Sprague-Dawley, Inc. (Indianapolis, 
IN), from virus-free colony 202A, at four weeks of age and were housed in polycarbonate cages (5/cage). The animals were maintained in containment facilities especially constructed for handling chemical carcinogens. The rooms were lighted $12 \mathrm{~h}$ each day and kept at $22+1^{\circ} \mathrm{C}$. The rats were fed a Teklad (4\%) diet ad libitum. OH-BBN was obtained from TCI America (Portland, OR) and cranberry juice concentrate was kindly provided by Ocean Spray Cranberries, Inc. (Lakeville, MA).

Six-week dose selection study. A dose selection study lasting six weeks was performed to determine a non-toxic dose of the cranberry juice concentrate. When the rats were 56 days of age, the administration of the cranberry concentrate by gavage (using water to dilute) was initiated as follows: Group 1, concentrate (no dilution); Group 2, concentrate (1:1 dilution); Group 3, concentrate (1:2 dilution); Group 4, concentrate (1:4 dilution) and Group 5, water only. The volume of each gavage was $1.0 \mathrm{ml}$ and was given daily, $7 \mathrm{x} /$ week, for six weeks. The rats were weighed $2 \mathrm{x} /$ week and checked daily for signs of toxicity. At termination of the study (98 days of age), all of the animals were necropsied and checked for gross lesions. Based on the data obtained, dose levels of 1.0 and $0.5 \mathrm{ml} / \mathrm{rat} /$ day of undiluted cranberry juice concentrate were selected for the long-term prevention study.

Chemoprevention study. Beginning when the female Fischer344 rats were 56 days of age, $\mathrm{OH}-\mathrm{BBN}$ was administered by gavage 2x/week for eight weeks. Each dose was $150 \mathrm{mg} \mathrm{OH}-$ $\mathrm{BBN}$ dissolved in $1.0 \mathrm{ml}$ ethanol-water $(25: 75 \mathrm{v} / \mathrm{v})$. The total dose of OH-BBN administered was, therefore, $2400 \mathrm{mg} / \mathrm{rat}$. The rats were treated with the cranberry concentrate starting one week after the final $\mathrm{OH}-\mathrm{BBN}$ dose and continuing until the end of the study (gavaged daily, $7 \mathrm{x} /$ week). The groups established were: Group 1, cranberry concentrate $(1.0 \mathrm{ml} / \mathrm{rat} /$ day); Group 2, cranberry concentrate $(0.5 \mathrm{ml} / \mathrm{rat} /$ day $)$ and Group 3, water only. Sufficient cranberry concentrate was initially obtained so that only one lot was used throughout the study. The study was terminated six months after the last OH-BBN treatment. The rats were observed daily, weighed weekly and palpated for urinary bladder lesions twice weekly. The animals were sacrificed when they developed a large palpable urinary bladder tumor or were observed to have bloody urine. At necropsy, the urinary bladders were weighed and then inflated with $10 \%$ buffered formalin. After fixation, the bladder was observed under a high intensity light for gross lesions. Each lesion was dissected and processed (H\&E-stained) for histological classification. Urinary bladder cancer incidence was analyzed by Fisher's exact test.

Determination of the total phenolics. The total phenolics in cranberry juice concentrate were determined by the FolinCiocalteu method with minor modifications (12). Briefly, $200 \mu \mathrm{l}$ of cranberry juice concentrate was diluted to $2 \mathrm{ml}$ in $80 \%$ methanol in water containing $0.1 \%$ formic acid. The solution was vortexed and further diluted 5-, 10- and 100-fold. Each sample (200 $\mu 1$, three replicates) was reacted with $1.0 \mathrm{ml}$ of the Folin-Ciocalteu reagent and $1.0 \mathrm{ml}$ of sodium carbonate $(7 \%)$. The reaction was thoroughly mixed and allowed to stand for $2 \mathrm{~h}$ at room temperature. The absorption at $726 \mathrm{~nm}$<smiles>O=c1c(O)c(-c2ccc(O)c(O)c2)oc2cc(O)cc(O)c12</smiles>

Figure 1. Chemical structure of quercetin.

was measured (Beckman Coulter, Inc., Fullerton, CA). The total phenolic content was expressed as vanillic acid equivalents in $\mathrm{mg} / \mathrm{ml}$.

Extraction and LC-MS analysis of cranberry juice concentrate. Cranberry juice $(0.5 \mathrm{ml})$ was extracted with $3 \mathrm{ml}$ of ethyl acetate twice and evaporated to dryness. The sample was reconstituted with $500 \mu 1$ of $80 \%$ methanol in water. LC-MS and LC-MS/MS analyses of the ethyl acetate extract of the cranberry juice were performed using a system consisting of a model SIL-HT refrigerated Shimadzu autosampler and HPLC instrument (Shimadzu Scientific Instruments, Inc., Columbia, MD), and an API 4000 mass spectrometer (Applied Biosystems/MDS Sciex, Concord, Ontario, Canada). Chromatography was carried out on a reversed-phase RP300 column (100x2.0 mm i.d.) pre-equilibrated with $10 \mathrm{mM}$ ammonium acetate $\left(\mathrm{NH}_{4} \mathrm{OAc}\right)$. Separations were effected by a linear gradient starting with 5\% B, 0-15 min; 80\% B, 16 min; $5 \% \mathrm{~B}$ and stopped at $20 \mathrm{~min}$. The column effluent was introduced into the mass spectrometer using electrospray ionization (ESI) in the negative mode. Nitrogen was used as a nebulizer, gas 1 and curtain gas. The nebulizer current and temperature were $5 \mathrm{amps}$ and $5000^{\circ} \mathrm{C}$, respectively. The collision gas (N2) was set at high and collision energy was $-45 \mathrm{eV}$. The LC-MS system was controlled by BioAnalyst 1.4 software.

Metabolic studies. Serum and urine were collected at 4 and $12 \mathrm{~h}$ after gavaging the rats with cranberry juice concentrate. The urine and serum samples were prepared by a liquid-liquid extraction method after hydrolysis. Apigenin was added as an internal standard to each sample $(0.5 \mathrm{ml}$ urine or $0.1 \mathrm{ml}$ serum) before hydrolysis with $\beta$-glucuronidase and aryl sulfatase in $150 \mathrm{mmol} / \mathrm{l}$ ammonium acetate buffer, $\mathrm{pH} 5.0$, for $16 \mathrm{~h}$ at $37^{\circ} \mathrm{C}$. The samples were extracted with hexane to remove neutral lipids, extracted with ethyl acetate, evaporated to dryness, and finally reconstituted in $100 \mu 180 \%$ aqueous methanol. LC-MS and MS/MS analyses were performed using a system consisting of a model SIL-HT refrigerated Shimadzu autosampler (Shimadzu Scientific Instruments, Inc.), and an API-III triple quadrupole mass spectrometer (PE Sciex, Concord, Canada). Chromatography was carried out on a 100x4.4 mm i.d. Aquapore RP-300 reversed-phase column (Perkin-Elmer, Shelton, CT) pre-equilibrated with $10 \mathrm{mM}$ ammonium acetate $\left(\mathrm{NH}_{4} \mathrm{OAc}\right)$.

Multiple reactions monitoring (MRM) was used to perform a mass spectrometric detection of quercetin and its metabolitemethyl quercetin in biological fluids. The MRM method 

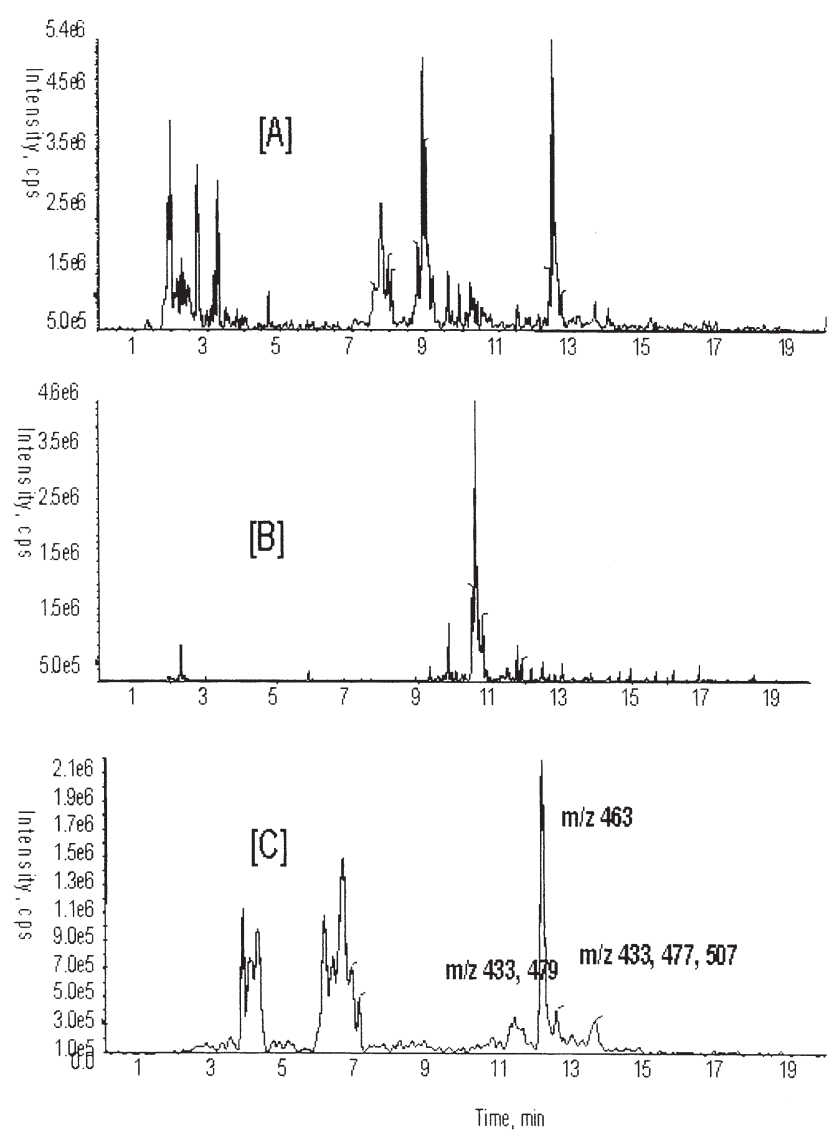

Figure 2. Extracted ion chromatograms for m/z 289 (A) and m/z 575 (B), obtained from cranberry juice concentrate by LC-ESI-MS in negative ion mode. The chromatogram (C) was obtained with a neutral loss of 162 from the extract in LC-MS/MS.

delivers a unique product ion that can be monitored and quantified in the midst of a complex biological matrix. For MRM, we developed a chromatographic run consisting of an isocratic of $30 \%$ acetonitrile in $10 \mathrm{mM} \mathrm{NH}_{4} \mathrm{OAc}$ with a flow rate of $0.1 \mathrm{ml} / \mathrm{min}$ over $10 \mathrm{~min}$. The column effluent was introduced into the mass spectrometer using electrospray ionization in negative mode. The voltage on the Ionspray interface was $-4900 \mathrm{~V}$ and the orifice potential was set at $-50 \mathrm{~V}$. Selected $[\mathrm{M}-\mathrm{H}]-($ deprotonated molecular ions) were analyzed by collision-induced dissociation with $90 \%$ argon to $10 \%$ nitrogen gas, and the product ion spectra were recorded. The MRM analysis was conducted by monitoring the precursor ion to product ion transitions from $\mathrm{m} / \mathrm{z} 301 / 151$ (quercetin), $301 / 272$ (quercetin), 315/299 (methyl quercetin) and 269/149 (apigenin). The chemical structure of quercetin is shown in Fig. 1.

\section{Results}

Total phenolics and LC-MS analysis of the cranberry juice extract. As mentioned earlier, cranberry is one of the richest sources of polyphenols. The standardization and quality control of cranberry juice concentrate is important when evaluating its biological activity. The Folin-Ciocalteu assay is widely used for the quantification of total phenolic content in food or dietary-supplemented products, and is based on the

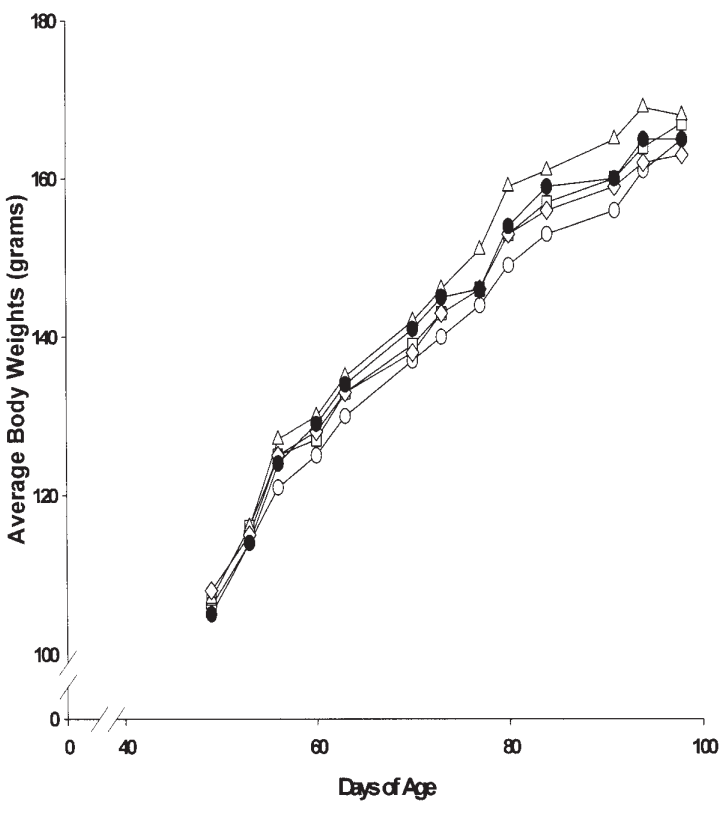

Figure 3. The body weights of female Fischer-344 rats receiving various concentrations of cranberry concentrate during the six-week dose selection study are shown. Dilutions of the concentrate were made by adding water. The various groups were: $\bullet$, controls (water only); $\bigcirc$, cranberry (no dilution); $\square$, cranberry (1:1 dilution); $\triangle$, cranberry (1:2 dilution) and $\diamond$, cranberry (1:4 dilution).

reaction of phenolic compounds with the reagent (13). The amount of total phenolics in cranberry juice concentrate was $9.57 \pm 0.50 \mathrm{mg}$ vanillic acid equivalent $/ \mathrm{ml}$. LC-MS and MS/MS techniques were also used to provide a qualitative analysis of cranberry polyphenols in the sample. LC-MS and MS/MS analyses of the ethyl acetate extract of cranberry juice showed several molecular ions corresponding to proanthocyanidins, anthocyanins, flavonoids and organic acids. The proanthocyanidin dimer A type (m/z 575) and monomeric catechin or epicatechin $(\mathrm{m} / \mathrm{z} 289)$, detected in the LC-MS analysis (Fig. 2) of the extract, were further identified by LC-MS/MS. Flavonoids and anthocyanins exist predominantly in conjugated form with various sugars (pentose and hexosides), which may significantly influence its bioavailability and absorption. As can be seen in Fig. 2, the ions $\mathrm{m} / \mathrm{z} 433$, $463,477,479$ and 507 are consistent with the presence of flavonoid or anthocyanin glycosides.

Animal studies. A dose selection study was performed in Fischer-344 rats using four doses of the cranberry concentrate. As shown in Fig. 3, even treatment with $1.0 \mathrm{ml} /$ day of the undiluted cranberry concentrate did not alter the body weight gain of the rats. No other signs of toxicity were evident during the study. Based on these data, doses of 1.0 and $0.5 \mathrm{ml}$ of the concentrate were selected to be gavaged daily $(7 \mathrm{x} /$ week) for the chemoprevention study.

Rats were administered cranberry juice concentrate by gavage beginning one week after the final carcinogen treatment in the prevention study (Table I). At the end of the study (six months after the final dose of $\mathrm{OH}-\mathrm{BBN}$ ), the urinary bladders containing the lesions were weighed. In the controls, the average weight of the bladder was $310 \mathrm{mg}$. Cranberry 
Table I. The effects of cranberry juice concentrate on $\mathrm{OH}-\mathrm{BBN}$-induced urinary bladder lesions.

\begin{tabular}{|c|c|c|c|c|c|c|c|}
\hline \multirow[b]{2}{*}{ Group } & \multirow[b]{2}{*}{ No. of rats } & \multirow[b]{2}{*}{ Carcinogen } & \multirow[b]{2}{*}{ Treatment } & \multicolumn{3}{|c|}{ Urinary bladder lesion } & \multirow{2}{*}{$\begin{array}{c}\begin{array}{c}\text { Bladder } \\
\text { lesions }\end{array} \\
\text { Weight (mg) }\end{array}$} \\
\hline & & & & Hyperplasia & Papilloma & Carcinoma & \\
\hline $1^{\mathrm{a}}$ & 29 & $\mathrm{OH}-\mathrm{BBN}$ & $\begin{array}{l}\text { Cranberry juice concentrate, } \\
\qquad 1.0 \mathrm{ml} / \text { day }\end{array}$ & $1.41(33 \% \downarrow)$ & $0.31(51 \% \downarrow)$ & $1.24(38 \% \downarrow)$ & $213(31 \% \downarrow)$ \\
\hline $2^{\mathrm{b}}$ & 29 & $\mathrm{OH}-\mathrm{BBN}$ & $\begin{array}{l}\text { Cranberry juice concentrate, } \\
\qquad 0.5 \mathrm{ml} / \text { day }\end{array}$ & $1.34(36 \% \downarrow)$ & $0.10(88 \% \downarrow)$ & $1.86(7 \% \downarrow)$ & $324(5 \% \uparrow)$ \\
\hline $3^{\mathrm{c}}$ & 28 & OH-BBN & None & 2.11 & 0.82 & 2.00 & 310 \\
\hline
\end{tabular}

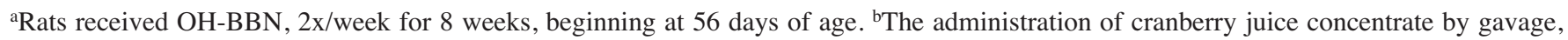
$7 \mathrm{x} /$ week, initiated one week after the final $\mathrm{OH}-\mathrm{BBN}$ treatment. ${ }^{\mathrm{c}}$ The average number and weight of urinary bladder lesions at the end of the study (six months after the final OH-BBN treatment).

Table II. Effects of cranberry juice concentrate on body weights and organ weights at end of the prevention study.

\begin{tabular}{lccccc}
\hline & & & \multicolumn{2}{c}{ Organ weights/100 g BW ratio } \\
\cline { 5 - 6 } Treatment & $\begin{array}{c}\text { Body weights } \\
\text { (grams) }\end{array}$ & Liver & Uterus & Ovaries & Kidneys \\
\hline Cranberry juice concentrate, $1.0 \mathrm{ml} /$ day & $214 \pm 2$ & $3.56 \pm 0.08$ & $0.32 \pm 0.03$ & $0.047 \pm 0.005$ & $0.86 \pm 0.03$ \\
Cranberry juice concentrate, $0.5 \mathrm{ml} /$ day & $215 \pm 9$ & $3.43 \pm 0.08$ & $0.32 \pm 0.04$ & $0.045 \pm 0.001$ & $0.87 \pm 0.01$ \\
None & $220 \pm 5$ & $3.49 \pm 0.09$ & $0.31 \pm 0.03$ & $0.046 \pm 0.001$ & $0.88 \pm 0.01$ \\
\hline
\end{tabular}

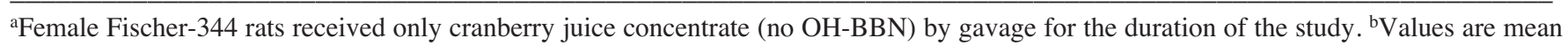
$\pm \mathrm{SEM}, \mathrm{N}=4$.

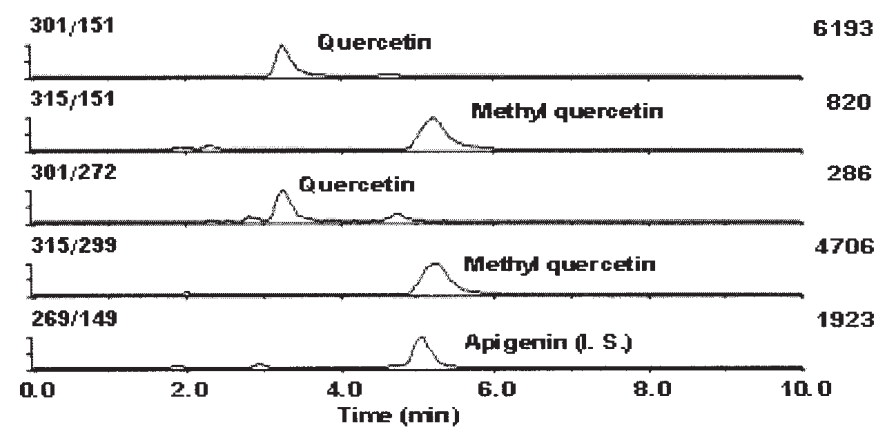

Figure 4. A representative MRM profile of a urine sample collected $4 \mathrm{~h}$ after the cranberry treatment. The numbers on the top right corner of each chromatogram represent the full-scale value of the ion abundance.

concentrate caused a reduction in the weight of the bladders by $31 \%$ at the high dose and $5 \%$ at the low dose, indicating a decrease in tumor size and suggesting a decrease in cell proliferation. With regard to bladder cancer multiplicity, the controls developed an average of 2.0 cancers $/$ rat, while $1.0 \mathrm{ml} /$ day of the cranberry concentrate caused a $38 \%$ reduction in the cancer number. Treatment with $0.5 \mathrm{ml} /$ day of the concen- trate caused a non-significant decrease of only $7 \%$ in the bladder cancer number. Decreases in the number of urinary bladder papillomas in the cranberry concentrate-treated rats were also observed, but because of the small number in the controls this was not considered to be biologically significant. The data collected for hyperplasia may have been even more significant had it not been for technical difficulties associated with accurately quantitating these lesions, particularly in the controls which tended to develop large palpable tumors that nearly filled the bladder (thus, making it difficult to count small hyperplastic lesions).

At the end of the study, the effects of cranberry juice concentrate on various organ weights were also determined. As examples, the weights of the liver, uterus, ovaries and kidneys are shown in Table II. Neither the weights nor histology of the organs were altered by administering the cranberry juice concentrate.

Analytical data. After a single dose of cranberry juice concentrate $(1.0 \mathrm{ml} / \mathrm{rat} /$ day $)$, urine and serum samples were collected and analyzed after B-D-glucuronidase and sulfatase hydrolysis. Quercetin and methyl quercetin in urine and serum samples were investigated in the MRM mode for higher sensitivity and selectivity. As can be seen in Fig. 4, quercetin and methyl quercetin were readily detected in the urine 
samples collected 4 and $12 \mathrm{~h}$ after cranberry juice concentrate treatment. Surprisingly, no quercetin was detected in the serum samples after enzymatic hydrolysis.

\section{Discussion}

The OH-BBN-induced model induces a high incidence of urinary bladder cancers in Fischer-344 rats within six months of carcinogen administration. The tumors are classified as transitional and squamous cell urinary bladder cancers or papillomas that are histologically similar to those occurring in humans (14-16). A genetic characterization of the cancers has only recently been started, but already two genes that are commonly associated with bladder cancers in humans, fragile histidine triad (FHIT) and survivin, have been shown to alter their expression in this model (17). This urinary bladder cancer model was previously used by our laboratories and by other investigators in the assessment of natural products and pharmaceutical compounds for their chemopreventive effects (16-19).

The data collected in this study suggest that cranberry juice concentrate may be inhibiting urinary bladder cancers by altering cell proliferation. Cranberries were recently shown to inhibit the induction of ornithine decarboxylase (ODC), an enzyme involved in tumor cell proliferation and in epithelial cells (20). In a comparison of the antiproliferation activities of 11 fruit-soluble free extracts on the growth of HepG2 human liver cancer cells in vitro, cranberries exhibited the highest activity in a dose-dependent manner (21). The inhibition of the proliferation of MCF-7 and MDA-MB-435 breast cancer cells has also been reported (22). Seeram and colleagues (9) found antiproliferative effects of total cranberry extracts and a polyphenol fraction of the extract in human oral, colon and prostate cancer cell lines. During the last few years, numerous studies have shown that NSAIDs, agents that inhibit cell proliferation, are highly active in the prevention of urinary bladder cancer. The OH-BBN model in either rats or mice has primarily been used in these studies. Rao and co-investigators (23) reported that aspirin, sulindac and ketoprofen were effective inhibitors of bladder carcinogenesis in mice. Other reports indicated that piroxicam, celecoxib and nimesulide were also active against $\mathrm{OH}-\mathrm{BBN}$-induced urinary bladder cancers $(10,24,25)$. These studies, therefore, indicate that bladder cancers can be prevented by agents that inhibit cell proliferation, and that cranberries contain compounds that have antiproliferative activity.

Several reports have indicated that cranberries contain compounds that have antioxidative actions (e.g., proanthocyanidins) that could influence carcinogen activation $(26,27)$. However, in our study, cranberry juice concentrate was not given until after carcinogen treatment so that the effect must have occurred on the promotion/progression stages of the carcinogenic process. Although our data suggest that the preventive efficacy of cranberries is due to the inhibition of cell proliferation, at least one report has demonstrated that cranberries can impair angiogenesis and, therefore, prevent tumor growth (28), suggesting another possible mechanism.

It is possible that the total phenolics or individual phenolic compounds in cranberry juice may be related to its preventive efficacy. The cranberry concentrate not only had high levels of phenolics $(9.57 \pm 0.50 \mathrm{mg}$ vanillic acid equivalent $/ \mathrm{ml})$ but also contained a wide range of phenolic compounds as indicated by the LC-MS analysis. Quercetin and its glycosides are the major phytochemicals of cranberry juice concentrate, and their metabolism and bioavailability are complex. Emerging evidence has indicated that these flavonoids are metabolized by UDP-glucuronyl transferase, sulfotransferases and methyl transferase forming several glucuronidated, sulfated and methylated conjugates, respectively, prior to reaching the systemic circulation (29-32). We, therefore, analyzed aglycone quercetin and its methyl derivative in the urine and serum samples after enzymatic hydrolysis.

The LC-MS analysis of the urine samples collected after gavaging cranberry juice concentrate showed peaks corresponding to quercetin and methyl quercetin. Further characterization by LC-MS/MS showed that the deprotonated molecular ion of quercetin had a prominent product ion at $\mathrm{m} / \mathrm{z} 151$. This product ion can be produced from a retro DielsAlder reaction, resulting in the cleavage of the heterocyclic ring of quercetin (33). This ion appears to be a diagnostic product ion for quercetin and its derivatives as it was also observed in the product ion spectrum of the ion at $\mathrm{m} / \mathrm{z} 315$.

Quercetin and methyl quercetin were also evaluated in the urine and serum samples using the MRM mode for higher sensitivity and selectivity. Although found in the urine, quercetin was not detected in the serum samples after enzymatic hydrolysis. Our results agree with a previous report that little or no quercetin is detected in the plasma after the ingestion of either pure aglycone or grape juice (34). A poor bioavailability of quercetin (mostly in the glycoside form) from red wine has also been reported (35). Previous studies have indicated that $75-99 \%$ of ingested quercetin glycosides are not recovered in urine and that the quercetin levels in human plasma rarely exceed $1 \mu \mathrm{M}$ after consuming a common quercetin-containing diet (36). The current data demonstrate that quercetin and its metabolites concentrate in the urine, and are available to the urinary bladder $>12 \mathrm{~h}$ after administration.

In summary, the present study shows for the first time that components of cranberry juice can prevent urinary bladder cancers in an in vivo model. Furthermore, the effect was observed when the cranberry juice concentrate was administered during the promotion/progression stage of the carcinogenic process. The decreased number and size of the urinary bladder cancers suggest that cranberry juice had an antiproliferative activity.

\section{Acknowledgements}

We wish to thank Ms. Mary Jo Cagle and Ms. Jeanne Hale for secretarial and editorial services, and Ms. Bonnie Mould and Mr. Tom Morgan for technical assistance. The studies were supported by Purdue-UAB Botanical Center for Age-Related Diseases funded by NCCAM P50 AT00477-05. Operation of the UAB Comprehensive Cancer Center Mass Spectrometry Shared Facility has been supported in part by a NCI Core Research Grant (NCI P30 CA13148-33).

\section{References}

1. Wakai K, Takashi M, Okamura K, et al: Foods and nutrients in relation to bladder cancer risk: a case-control study in Aichi Prefecture, Central Japan. Nutr Cancer 38: 13-22, 2000. 
2. Nagano J, Kong S, Preston DL, et al: Bladder-cancer incidence in relation to vegetable and fruit consumption: a prospective study of atomic-bomb survivors. Int J Cancer 86: 132-138, 2000.

3. Chen JJ, Ye ZQ and Koo MW: Growth inhibition and cell cycle arrest effects of epigallocatechin gallate in the NBT-II bladder tumour cell line. BJU Int 93: 1082-1086, 2004.

4. Kemberling JK, Hampton JA, Keck RW, Gomez MA and Selman SH: Inhibition of bladder tumor growth by the green tea derivative epigallocatechin-3-gallate. J Urol 170: 773-776, 2003.

5. Vinson JA, Su X, Zubik L and Bose P: Phenol antioxidant quantity and quality in foods: fruits. J Agric Food Chem 49: 5315-5321, 2001.

6. Howell $\mathrm{AB}$ and Foxman B: Cranberry juice and adhesion of antibiotic-resistent uropathogens. JAMA 287: 3082-3083, 2002.

7. Larocca LM, Giustacchini M, Maggiano N, et al: Growthinhibitory effect of quercetin and presence of type II estrogen binding sites in primary human transitional cell carcinomas. J Urol 152: 1029-1033, 1994.

8. Hirose M, Fukushima S, Sakata T, Inui M and Ito N: Effect of quercetin on two-stage carcinogenesis of the rat urinary bladder. Cancer Lett 21: 23-27, 1983.

9. Seeram NP, Adams LS, Hardy ML and Heber D: Total cranberry extract versus its phytochemical constituents: antiproliferative and synergistic effects against human tumor cells. J Agric Food Chem 52: 2512-2517, 2004.

10. Grubbs CJ, Lubet RA, Koki AT, et al: Celecoxib inhibits Nbutyl-N-(4-hydroxybutyl)-nitrosamine-induced urinary bladder cancers in male B6D2F1 mice and female Fischer-344 rats. Cancer Res 60: 5599-5602, 2000.

11. Yan X, Murphy BT, Hammond GB, Vinson JA and Neto CC: Antioxidant activities and antitumor screening of extracts from cranberry fruit (Vaccinium macrocarpon). J Agric Food Chem 50: 5844-5849, 2002.

12. Singleton VL and Rossi JA: Colorimetry of total phenolics with phosphomolydic-phosphotungstic acid reagents. Am J Enol Vitic 16: 144-158, 1965.

13. Prior RL, Wu X and Schaich K: Standardized methods for the determination of antioxidant capacity and phenolics in foods and dietary supplements. J Agric Food Chem 53: 4290-4302, 2005.

14. McCormick DL, Ronan SS, Becci PJ and Moon RC: Influence of total dose and dose schedule on induction of urinary bladder cancer in the mouse by N-butyl-N-(4-hydroxybutyl)nitrosamine. Carcinogenesis 2: 251-254, 1981

15. Becci PJ, Thompson HJ, Strum JM, Brown CC and Sporn MB: N-butyl-N-(4-hydroxybutyl)nitrosamine-induced urinary bladder cancer in C57BL/6 X DBA/2 F1 mice as a useful model for study of chemoprevention of cancer with retinoids. Cancer Res 41: 927-932, 1981.

16. Grubbs CJ, Moon RC, Squire RA, et al: 13-cis-Retinoic acid: inhibition of bladder carcinogenesis induced in rats by N-butylN-(4-hydroxybutyl)nitrosamine. Science 198: 743-744, 1977.

17. Lubet RA, Huebner K, Fong LYY, et al: 4-Hydroxybutyl(butyl)nitrosamine-induced urinary bladder cancers in mice: characterization of FHIT and survivin expression and chemopreventive effects of indomethacin. Carcinogenesis 26: 571-578, 2005 .

18. Vinh PQ, Sugie S, Tanaka T, et al: Chemopreventive effects of a flavonoid antioxidant silymarin on N-butyl-N-(4-hydroxybutyl)nitrosamine-induced urinary bladder carcinogenesis in male ICR mice. Jpn J Cancer Res 93: 42-49, 2002.
19. Okazaki K, Umemura T, Imazawa T, et al: Enhancement of urinary bladder carcinogenesis by combined treatment with benzyl isothiocyanate and N-butyl-N-(4-hydroxybutyl) nitrosamine in rats after initiation. Cancer Sci 94: 948-952, 2003.

20. Kandil FE, Smith MA, Rogers RB, et al: Composition of a chemopreventive proanthocyanidin-rich fraction from cranberry fruits responsible for the inhibition of 12-O-tetradecanoyl phorbol-13-acetate (TPA)-induced ornithine decarboxylase (ODC) activity. J Agric Food Chem 50: 1063-1069, 2002.

21. Sun J, Chu YF, Wu X and Liu RH: Antioxidant and antiproliferative activities of common fruits. J Agric and Food Chem 50: 7449-7454, 2002.

22. Guthrie N: Effect of cranberry juice and products on human breast cancer cell growth. Proc Exper Biology Conf 53: 13, 2000.

23. Rao KV, Detriac CJ, Steele VE, et al: Differential activity of aspirin, ketoprofen and sulindac as cancer chemopreventive agents in the mouse urinary bladder. Carcinogenesis 17: 1435-1438, 1996.

24. Moon RC, Kelloff GJ, Detriac CJ, et al: Chemoprevention of OH-BBN induced bladder cancer in mice by piroxicam. Carcinogenesis 14: 1487-1489, 1993.

25. Okajima E, Denda A, Ozono S, et al: Chemopreventive effects of nimesulide, a selective cyclooxygense- 2 inhibitor, on the development of rat urinary bladder carcinomas initiated by $\mathrm{N}$ butyl-N-(4-hydroxybutyl)nitrosamine. Cancer Res 58: 3028-3031, 1998.

26. Ariga T: The antioxidative function, preventive action on disease and utilization of proanthocyanidins. Biofactors 21: 197-201, 2004.

27. Valentova K, Stejskal D, Bednar P, et al: Biosafety, antioxidant status, and metabolities in urine after consumption of dried cranberry juice in healthy women: a pilot double-blind placebocontrolled trial. J Agric Food Chem 55: 3217-3224, 2007.

28. Roy S, Khanna S, Alessio HM, et al: Anti-angiogenic property of edible berries. Free Radic Res 36: 1023-1031, 2002.

29. Moon JH, Tsushida T, Nakahara K and Terao J: Identification of quercetin 3-O-beta-D-glucuronide as an antioxidative metabolite in rat plasma after oral administration of quercetin. Free Radic Biol Med 30: 1274-1285, 2001.

30. Wittig J, Herderich M, Graefe EU and Veit M: Identification of quercetin glucuronides in human plasma by high-performance liquid chromatography-tandem mass spectrometry. J Chromatogr B Biomed Sci Appl 753: 237-243, 2001.

31. Graf BA, Mullen W, Caldwell ST, et al: Disposition and metabolism of [2-14C]quercetin-4'-glucoside in rats. Drug Metab Dispos 33: 1036-1043 2005.

32. Hong YJ and Mitchell AE: Metabolic profiling of flavonol metabolites in human urine by liquid chromatography and tandem mass spectrometry. J Agric Food Chem 52: 6794-6801, 2004.

33. Fabre N, Rustan I, de Hoffmann E and Quetin-Leclercq J: Determination of flavone, flavonol and flavanone aglycones by negative ion liquid chromatography electrospray ion trap mass spectrometry. J Am Soc Mass Spectrom 12: 707-715, 2001.

34. Meng X, Maliakal P, Lu H, Lee MJ and Yang CS: Urinary and plasma levels of resveratrol and quercetin in humans, mice, and rats after ingestion of pure compounds and grape juice. J Agric Food Chem 52: 935-942, 2004

35. de Vries JH, Hollman PC, van Amersfoort I, Olthof MR and Katan MB: Red wine is a poor source of bioavailable flavonols in men. J Nutr 131: 745-748, 2001

36. Hollman PC, van Trijp JM, Buysman MN, et al: Relative bioavailability of the antioxidant flavonoid quercetin from various foods in man. FEBS Lett 418: 52-156, 1997. 